\title{
Predictors of Emotional Distress and Wellbeing 2-5 Years After Stroke
}

\author{
H. Bergersen, ${ }^{1}$ A.-K. Schanke, ${ }^{1}$ and K. S. Sunnerhagen ${ }^{1,2}$ \\ ${ }^{1}$ Sunnaas Rehabilitation Hospital, Bjørnemyrveien 11, 1450 Nesoddtangen, Norway \\ ${ }^{2}$ Rehabiliation Medicine, University of Gothenburg, Per Dubbsgatan 14, 3rd Floor, 41345 Goteborg, Sweden \\ Correspondence should be addressed to K. S. Sunnerhagen; ks.sunnerhagen@neuro.gu.se
}

Received 11 January 2013; Accepted 6 February 2013

Academic Editors: R. P. Kessels and D. Qu

Copyright (c) $2013 \mathrm{H}$. Bergersen et al. This is an open access article distributed under the Creative Commons Attribution License, which permits unrestricted use, distribution, and reproduction in any medium, provided the original work is properly cited.

\begin{abstract}
Objectives. To identify predictors of emotional distress and psychological wellbeing in stroke survivors 2-5 years after discharge from comprehensive rehabilitation. Material and Methods. The Hospital Anxiety and Depression Scale (HADS), the General Health Questionnaire (GHQ-30), and questions regarding life situations were mailed to former patients. Multiple regression analyses were performed. Results. The responses from 68 participants (37\% women), of an average age of 58 years old, were used. Emotional distress (HADS $>10$ ) was identified in $41 \%$. Well-being (GHQ-30<6) was identified in $46 \%$. Not surprisingly, there was a strongly negative association between well-being $(\mathrm{GHQ}-30<6)$ and emotional distress (HADS > 10) at follow up. Dependency in toileting during rehabilitation predicted emotional distress $2-5$ years later. Finally, well-being at followup was predicted by age $>65$ years, independent mobility, perceiving proxies as supportive, and being in employment. Conclusions. Dependence in the activities of daily living 3-6 months after-injury predicted emotional distress 2-5 years after-stroke. Being over 65 years, having an occupation, proxy support and being less dependent all predicted well-being. Emotional distress and well-being were clearly negatively associated. Gender, education, marital status, and type of stroke were not associated with the outcome measures.
\end{abstract}

\section{Introduction}

The burden of stroke is high worldwide [1]. In Norway, stroke has a prevalence of 19 per 1000 in people above 20 years old, and it is the largest cause of severe disability in the elderly [2]. Sensory, motor, cognitive, and emotional sequelae after stroke are often chronic and have a significant negative impact on the ability of patients to carry out everyday activities, thereby increasing their dependence on caregivers. The economic and welfare consequences for both society and the patients are severe.

It is well known that psychosocial distress such as anxiety, depression, social withdrawal, and reduced quality of life is common in the first few months after stroke [3]. The level of wellbeing and mental health more than 1 year after stroke are unfortunately less well studied, but studies have shown that related symptoms can prevail for a long time [4]. A study of the quality of life 2 years after stroke concluded that " $(. .$. people in the general community would rather give up half of their remaining years of life to live in full health than continue living with the health status of the average stroke survivor" [5]. Following acute stroke, a reduced social network one or several years later was associated with a decreased quality of life $[6,7]$ and with mood disorders [8].

Physical and cognitive disability and dependency during activities of daily living (ADL) have been found to be related to reduced quality of life and mood disturbances [9-11] at all time points following stroke. However, Löfgren et al. [12] found no association between disability or social support and reduced quality of life 3 years after-stroke. A history of mental health problems has not been found to be associated with mood disorders in the long-term post stroke $[3,13]$. Lesion location was not systematically associated with depression in a systematic review where most of the patients had been assessed within 1 year after stroke [14]. The results regarding associations with age, gender, cognitive deficits, and marital status are highly divergent $[7,12,15,16]$. Anxiety has been studied less than depression among stroke patients. 
Some people seem to be at greater risk of developing chronic emotional problems. Others seem to be hardy and experience psychological wellbeing despite suffering from a stroke. In clinical practice, there is a need for the early identification of patients who are psychologically vulnerable and at risk of developing emotional problems. In this study, we aimed to identify predictors of stroke survivors' emotional distress and psychological wellbeing 2-5 years after discharge from 3 to 6 months of comprehensive rehabilitation.

\section{Materials and Methods}

A survey was sent 2-4 years after discharge [17] to patients who had been admitted to the Sunnaas Rehabilitation Hospital during a 3-year period and who were still alive (251); of these, $64 \%$ responded. In the present study, the focus was on lesion location, ADL capacity, and cognitive function; information on all these was available for 68 patients $(n=68)$. The group consisted of $37 \%$ women and $63 \%$ men, with a mean age of 58 years, who were admitted to the hospital at a median of 56 days after injury (14-352 days).

The survey contained structured questions regarding psychosocial situation (civil status, employment, driving licence, and satisfaction with support from family and friends, help from the home care), the Hospital Anxiety and Depression Scale (HADS) [18], and the General Health Questionnaire (GHQ) [19].

The HADS is a 14 -item questionnaire that consists of anxiety (HADS-A) and depression (HADS-D) subscales. It has good psychometric properties [20] and is well suited for assessing symptom severity in stroke patients [21, 22]. Anxiety and depression both seem to correlate more strongly with the total score (HADS-T) than with the subscales, and HADS-T has been suggested as a measure of general emotional distress in stroke patients $[22,23]$. A cutoff point of $10 / 11$ is typically applied, where a HADS-T score of greater than 10 indicates clinically significant emotional distress.

The General Health Questionnaire (GHQ) [19] has been suggested to be suitable for screening mild psychopathology, quality of life, and psychological wellbeing. The version with 30 items ("GHQ-30") contains more items on quality of life and fewer items on somatic symptoms compared to other versions of the GHQ, and it is regarded as being well suited to patients in primary care as well as in somatic hospitals. Each item is coded to 0 or 1 . A total score of $\geq 6$ indicates poor wellbeing. Wellbeing is indicated by scores of $\leq 5$ on the GHQ-30. An authorized Norwegian version of the GHQ-30 was used.

2.1. Objective Assessments. Medical and demographic information was gathered from the participants' hospital charts. The modified Rankin Scale (mRS) [24] was used to describe overall disability. The ADL were assessed using the Sunnaas' ADL index [25] or the Functional Independence Measure (FIM) [26]. For this paper, four functional areas were defined: "verbal communication," "dressing," "continence and toileting" and "indoor mobility" (except stairs and toilet), which were all scored as "independent" of or "dependent" on help. Cognitive function was assessed as part of the hospital's clinical routine. Areas that were tested were verbal comprehension and abstraction ("similarities" from the Wechsler Adult Intelligence Scale (WAIS) and the "Token test"), constructional functions, visuospatial perception, visual attention/neglect, and visual abstraction (copying of two- and three-dimensional Greek crosses, "Block Assembly" from the WAIS, letter- or star-cancellation tests, and "Raven's Colored Matrices" for children or "Matrices" from the WAIS). In addition, visuomotor coordination and speed were measured with the "Grooved Pegboard Test" from the HalsteadReitan/Matthews-Kløve battery. A number of patients also went through a structured interview for the orientation and assessment of apraxia. Since the neuropsychological data were collected for clinical purposes, the tests were selected according to what was considered relevant for the patient. The participants' test protocols were examined by two experienced neuropsychologists (the first and second authors). Overall cognitive function was then categorized as from 1 to 4 : (1) mild cognitive deficits (no cognitive functions $\geq 2$ SD below the normative mean); (2) moderate cognitive deficits (some focal deficits, but not generalized cognitive impairment (abstraction or psychomotor speed or mental efficiency $\geq 2$ SD below the normative mean); (3) severe cognitive deficits (focal and general deficits $\geq 2$ SD below the normative mean); or (4) global cognitive deficits (all cognitive functions $\geq 2$ SD below the normative mean).

\section{Statistical Analyses}

The Statistical Packages for Social Sciences (SPSS) software program, version 17.0, was used for the statistical analyses. Counts and percentages were used to describe categorical data, while means and standard deviations (SD) were used as descriptive measures of numerical data. The agreement between emotional distress and wellbeing was explored in cross tabulations and quantified by Cohen's $\kappa$ coefficient. A $\kappa$ coefficient in the range from 0.40 to 0.80 is considered moderate to good and those exceeding 0.80 very good, whereas values below 0.40 are fair to poor. Dummy variables corresponding to the four cognitive categories described previously were used to enter the level of overall cognitive functioning in regression analyses. A dichotomized cognitive variable termed "General cognitive deficits" was established by collapsing mild and moderate cognitive deficits and severe and global cognitive deficits. Continuous explanatory variables were dichotomized where considered appropriate. Different categories were explored for "time since stroke," "overall cognitive function," and "practical (MRS) function."

Spearman's correlations were used to check for colinearity between the explanatory variables. Associations between explanatory variables and outcome measures were explored with univariate logistic regression analyses. All variables with a $P$ value $\leq 0.2$ in the univariate analyses were included in multivariable analyses using stepwise backwards LR regression analyses with exclusion/inclusion criteria of $P<0.1$. The respondents' raw scores on the GHQ and HADS were also included among the explanatory variables. In order to determine the contribution of excluded variables 
TABLE 1: Demographic, injury-related and psychosocial variables for 68 participants with stroke. Numbers are $n(\%)$ unless specified otherwise.

\begin{tabular}{|c|c|}
\hline & $n(\%)$ \\
\hline Mean age in years $(\mathrm{SD})$, range & $\begin{array}{l}58.4(11.7) \\
23-85\end{array}$ \\
\hline \multicolumn{2}{|l|}{ Gender } \\
\hline Female & $25(37 \%)$ \\
\hline Male & $43(63 \%)$ \\
\hline Mean years of education (SD), range & $\begin{array}{l}11.9(3.1) \\
7-18\end{array}$ \\
\hline \multicolumn{2}{|l|}{ Side of lesion } \\
\hline Right hemisphere & $28(41 \%)$ \\
\hline Left hemisphere & $40(59 \%)$ \\
\hline \multicolumn{2}{|l|}{ Earlier strokes } \\
\hline Yes & $2(3 \%)$ \\
\hline No & $64(94 \%)$ \\
\hline Missing & $2(3 \%)$ \\
\hline Mean duration of illness in months (SD), range & $\begin{array}{l}3.5(1.1) \\
1.5-5.4\end{array}$ \\
\hline \multicolumn{2}{|l|}{$\begin{array}{l}\text { Practical and cognitive function during } \\
\text { rehabilitation at Sunnaas Rehabilitation Hospital }\end{array}$} \\
\hline Modified Rankin Scale (MRS) mean (SD), range & $\begin{array}{l}3^{1}(0.8) \\
2-4\end{array}$ \\
\hline MRS $>2$ & $44(65 \%)$ \\
\hline \multicolumn{2}{|l|}{ Dependence in $\mathrm{ADL}$} \\
\hline Verbal communication (dependent) & $20(29 \%)$ \\
\hline Toileting and continence (dependent) & $9(13 \%)$ \\
\hline Dressing (dependent) & $16(24 \%)$ \\
\hline Indoors mobility (dependent) & $11(16 \%)$ \\
\hline \multicolumn{2}{|l|}{$\begin{array}{l}\text { Overall cognitive function: severity of cognitive } \\
\text { deficits }\end{array}$} \\
\hline $\begin{array}{l}\text { Mild (all cognitive functions }<2 \text { SD below the } \\
\text { mean) }\end{array}$ & $21(31 \%)$ \\
\hline $\begin{array}{l}\text { Moderate (some focal deficits } \geq 2 \text { SD below the } \\
\text { mean) }\end{array}$ & $25(37 \%)$ \\
\hline $\begin{array}{l}\text { Severe (general }+ \text { some focal deficits } \geq 2 \text { SD } \\
\text { below the mean) }\end{array}$ & $14(21 \%)$ \\
\hline $\begin{array}{l}\text { Global (all cognitive functions } \geq 2 \text { SD below } \\
\text { the mean) }\end{array}$ & $8(12 \%)$ \\
\hline $\begin{array}{l}\text { Block Assembly, age-scaled score }(n=65) \text {, } \\
\text { mean (SD), and range }\end{array}$ & $\begin{array}{c}6.9(1.8) \\
0-15\end{array}$ \\
\hline $\begin{array}{l}\text { Raven's Coloured Matrices, t score }(n=59) \text {, } \\
\text { mean (SD), and range }\end{array}$ & $\begin{array}{l}44.7(19.0) \\
0-81\end{array}$ \\
\hline \multicolumn{2}{|l|}{ Occupational status at followup } \\
\hline Employment & $16(24 \%)$ \\
\hline Disability pension & $32(47 \%)$ \\
\hline Age retirement & $20(29 \%)$ \\
\hline \multicolumn{2}{|l|}{ Civic status at followup } \\
\hline Single (widowed/divorced/never married) & $17(25 \%)$ \\
\hline Married/cohabitant & $51(75 \%)$ \\
\hline
\end{tabular}

TABLE 1: Continued.

\begin{tabular}{lc}
\hline & $n(\%)$ \\
\hline $\begin{array}{l}\text { Self-reported satisfaction at followup (yes, clearly } \\
\text { satisfied) }\end{array}$ & $60(89 \%)$ \\
$\quad \begin{array}{l}\text { Psychosocial support from proxies }(n=68) \\
\quad \text { Community home service and rehabilitation }\end{array}$ & $44(67 \%)$ \\
$\quad \begin{array}{l}\text { services }(n=66) \\
\text { Self-reported emotional distress at followup } \\
\quad \text { HADS }>10)\end{array}$ & $28(41 \%)$ \\
$\quad \begin{array}{l}\text { Self-reported wellbeing at followup } \\
\text { (GHQ-30 < 6) }\end{array}$ & $31(46 \%)$ \\
\hline${ }^{1}$ Moderate disability, requiring some help, but able to look after own affairs.
\end{tabular}

to the final models, these were entered into the models separately. Logistic multiple backwards and forwards logistic regression analyses with a 0.1 limit for inclusion and a 0.05 limit for exclusion were performed to build the final models for wellbeing and emotional distress.

\section{Ethics}

The study was approved by the Regional Committee for Medical Research Ethics, South-Eastern Norway and was conducted in agreement with the Helsinki declaration. It was also approved by the Data Inspectorate.

\section{Results}

The study group (Table 1) was quite disabled by their stroke; $35 \%$ (34 patients) had an MRS score of 4, corresponding to a "moderately severe disability; unable to walk without assistance and unable to attend to own bodily needs without assistance." Only $31 \%$ had mild cognitive deficits, which corresponded to a deficit $<2$ below the normative mean, indicating that the majority of the study group had significant cognitive impairment.

The neuropsychological tests other than the two nonverbal tests (Block Assembly and Raven's Colored Matrices) showed no association with the outcome measures and are not included in Table 1.

Twenty-four percent $(n=16)$ were in paid work at the time of followup (but only two were above 59 years old). Twothirds $(n=11)$ of these worked part time, had an adjusted vocational situation, or were on sick leave. The driver's licence had been revoked in $44 \%$ due to reduced function after the stroke. The marital status and number of divorces were comparable to the same age group in the general Norwegian population.

A chi-square test for independence (with Yates' Continuity Correction) revealed an association between the two outcome measures $\left(\chi^{2}(1, n=68)=12 ; P=0.001 ; \varphi=\right.$ .44 ), meaning that low distress covaried with high levels of wellbeing and vice versa. The agreement between the measures was $\kappa=0.4$, which is to be considered as fair. This indicates that the dichotomized GHQ-30 and HADS, although with significantly related outcome measures, also measure distinct aspects of wellbeing and emotional distress. 
TABLE 2: Association between explanatory variables and wellbeing and emotional distress at followup.

\begin{tabular}{|c|c|c|c|}
\hline \multicolumn{2}{|c|}{ Explanatory variables (predictors) $(n=68)$} & $\begin{array}{c}\text { Wellbeing }^{1} \\
(\mathrm{GHQ}-30<6) \\
\beta(P)\end{array}$ & $\begin{array}{c}\text { Distress }^{1} \\
(\mathrm{HADS}>10) \\
\beta(P)\end{array}$ \\
\hline \multirow{3}{*}{ Demographic variables } & Age $(0 \leq 65)$ & $-0.71(0.21)$ & $0.00(1.00)$ \\
\hline & $\operatorname{Sex}(0=$ female $)$ & $-0.36(0.48)$ & $0.70(\mathbf{0 . 1 7})$ \\
\hline & Education ( $0 \leq 12$ years $)$ & $0.33(0.51)$ & $-0.12(0.81)$ \\
\hline \multirow{4}{*}{ Medical variables } & Stroke type ( $0=$ ischaemic infarction $)$ & $0.01(0.99)$ & $-0.55(0.37)$ \\
\hline & Side of lesion ( 0 = left hemisphere) & $0.19(0.71)$ & $0.87(\mathbf{0 . 0 9})$ \\
\hline & Time since stroke onset ( $0 \leq 3$ years) & $0.67(0.20)$ & $0.41(0.43)$ \\
\hline & Time since stroke onset $(0=2.5-4$ years $)$ & $0.32(0.52)$ & $0.09(0.86)$ \\
\hline \multirow{5}{*}{ ADL variables } & MRS $(0=$ Modified Rankin Scale $<3)$ & $0.54(0.30)$ & $0.24(0.65)$ \\
\hline & Verbal communication $(0=$ independent $)$ & $0.62(0.26)$ & $0.22(0.68)$ \\
\hline & Toileting $(0=$ independent $)$ & $0.60(0.43)$ & $1.85(0.03)$ \\
\hline & Dressing $(0=$ independent $)$ & $0.43(0.46)$ & $1.15(\mathbf{0 . 0 5})$ \\
\hline & Mobility ( 0 = independent) & $1.54(\mathbf{0 . 0 6})$ & $1.60(0.03)$ \\
\hline \multirow{7}{*}{ Cognition } & Mild cognitive deficits $(0=$ no $)$ & $0.40(0.45)$ & $0.48(0.38)$ \\
\hline & Moderate cognitive deficits ${ }^{2}(0=$ no $)$ & $0.36(0.48)$ & $-0.08(0.88)$ \\
\hline & Severe cognitive deficits ${ }^{2}(0=$ no $)$ & $-0.59(0.33)$ & $0.09(0.87)$ \\
\hline & Global cognitive deficits $(0=$ no $)$ & $1.03(0.23)$ & $0.99(0.20)$ \\
\hline & General cognitive deficits ${ }^{3}(0=$ no $)$ & $0.01(0.99)$ & $0.53(0.31)$ \\
\hline & Nonverbal problem solving: Block Assembly $(n=65)$ & $-0.08(\mathbf{0 . 1 6})$ & $-0.13(0.04)$ \\
\hline & Raven's Colored Matrices $(n=59)$ & $-0.02(\mathbf{0 . 1 7})$ & $-0.02(0.20)$ \\
\hline \multirow{5}{*}{$\begin{array}{l}\text { Psycho social variables } \\
\text { at followup }\end{array}$} & Marital status $(0=$ married/cohabitant $)$ & $-0.39(0.48)$ & $-0.33(0.57)$ \\
\hline & Occupation $(0=$ work; $1=$ pension $)$ & $0.90(\mathbf{0 . 1 3})$ & $-0.47(0.41)$ \\
\hline & Driver's licence $(0=$ revoked $)$ & $-0.96(\mathbf{0 . 0 6})$ & $0.08(0.88)$ \\
\hline & Proxy support ( 0 = satisfied with $)$ & $1.95(\mathbf{0 . 0 8})$ & $0.41(0.59)$ \\
\hline & Community services $(0=$ satisfied with $)$ & $-0.55(0.30)$ & $0.00(1.00)$ \\
\hline
\end{tabular}

\footnotetext{
${ }^{1}$ Poor wellbeing $=0$. Not emotionally distressed $=0$.

${ }^{2}$ As moderate and severe deficits are dummy variables, persons with "not" moderate or severe cognitive deficits have either milder or more severe deficits. For definitions, see Table 1.

${ }^{3}$ Cognitive functions dichotomized in "mild" or "severe" (0) or "moderate" or "global" (1) deficits.

Note. Significant variables $(P<0.05)$ and $P$ values $<0.2$ are bold.
}

Forty-one percent $(n=28)$ of the participants experienced emotional distress (HADS $>10)$, and $46 \%(n=31)$ perceived wellbeing (GHQ-30 cases $<6$ ). The majority of the 28 participants who reported emotional distress did not perceive wellbeing $(n=23)$, but 5 reported both high emotional distress and wellbeing. These five participants had a median score on the HADS anxiety and depression subscales of 7 (range 5-10), indicating borderline clinical symptoms.

Further inspection of the data did not reveal any other common characteristics that could obviously help to explain the participants' perception of wellbeing despite experiencing distress. Fifteen (38\%) of the participants who did not report emotional distress reported poor wellbeing. Associations between the explanatory variables and the outcome measures are shown in Table 2.

Table 3 presents the models that best predicted wellbeing and emotional distress. Multiple regression analyses without the two outcome measures of emotional distress (HADS > $10)$ and wellbeing (GHQ-30<6) were also performed, which gave almost identical results. The models in Table 3 had a
Nagelkerke $R^{2}$ value for distress of 0.49 and a value for wellbeing of 0.58 .

\section{Discussion}

The aim of the present study was to identify predictors of emotional distress and wellbeing among severely injured stroke survivors 2-5 years after injury. We investigated the predictive value of a range of demographic, medical, and cognitive factors in predicting the level of emotional distress and wellbeing 2-5 years after injury. The study revealed that there was a fair degree of overlap in the content of the two outcome measures: emotional distress (dichotomized HADS) and wellbeing (dichotomized GHQ-30), indicating that the two measures contain both similar and different qualities of subjective feelings and experiences. The level of disability and dependence in daily life were significant predictors of mental health and wellbeing. This is in accordance with other long-term followup studies [7, 8, 11, 27]. More specifically, dependence in the toilet situation significantly predicted 
TABLE 3: Regression models of emotional distress or wellbeing.

\begin{tabular}{|c|c|c|c|c|c|c|}
\hline \multirow{2}{*}{ Outcome } & \multirow{2}{*}{$B$} & \multirow{2}{*}{ S.E. } & \multirow{2}{*}{$P$} & \multirow{2}{*}{$\mathrm{OR}^{2}$} & \multicolumn{2}{|c|}{$95 \% \mathrm{CI}$} \\
\hline & & & & & Lower & Upper \\
\hline \multicolumn{7}{|c|}{ Explanatory variable (predictors) $^{1}$} \\
\hline \multicolumn{7}{|l|}{ Emotional distress $^{3}$} \\
\hline Dependent toileting & 2.1 & 1.0 & 0.033 & 8.5 & 1.2 & 60.7 \\
\hline Low wellbeing (GHQ > 5) & 0.21 & 0.05 & 0.000 & 1.2 & 1.1 & 1.4 \\
\hline \multicolumn{7}{|l|}{ Wellbeing } \\
\hline Occupation & 2.6 & 1.1 & 0.013 & 13.6 & 1.7 & 107.0 \\
\hline Age $>65$ years & -2.6 & 1.0 & 0.008 & 0.08 & 0.01 & 0.51 \\
\hline Satisfaction with proxy support & 2.8 & 1.4 & 0.039 & 0.06 & 0.004 & 0.86 \\
\hline Independent mobility ${ }^{4}$ & 2.1 & 1.3 & 0.095 & 8.2 & 0.69 & 97.8 \\
\hline Not distressed $($ HADS < 11$)$ & 0.25 & 0.07 & 0.000 & 1.3 & 1.1 & 1.5 \\
\hline
\end{tabular}

${ }^{1}$ Sex, education, stroke type, side of lesion, time since stroke onset, MRS, verbal communication, cognitive deficits, marital status (living alone or not), Driver's licence, and satisfaction with community services did not significantly explain wellbeing or emotional distress.

${ }^{2}$ Odds ratio/exp $(B)$.

${ }^{3}$ Due to co-linearity Raven's, mobility and dressing were excluded. Backwards analysis resulted in the same model.

${ }^{4}$ Included in the model in the forwards analyses and excluded from the model in the backwards analyses.

emotional distress, which was also found in earlier 1 and 4 year followup studies [11,28]. Independence in dressing and indoor mobility was also associated with emotional distress. Due to colinearity, these two ADL variables were not included in the regression analysis together with toileting. When they replaced toileting in the regression analyses, both significantly explained emotional distress, although with somewhat weaker values. It has previously been found that stroke survivors' dependence on others in primary ADL functions does not typically change after the first 3 months [29]. Hence, the dependence in ADL at followup can be assumed to reflect the respondents' ADL functioning at discharge from the rehabilitation hospital 2-5 years previously. Some stroke survivors adjust to the fact that they are dependent upon help in their private daily life activities, but the study shows that many do not, and this situation reduces wellbeing and increases the risk of developing emotional distress.

Occupational status predicted wellbeing even when controlling for age and physical disability. Being employed increases wellbeing. Unlike in the results of some other studies [11,30], the level of cognitive impairment did not significantly predict wellbeing, although some nonverbal neuropsychological tests were associated with emotional distress in the univariate analyses. The impacts of mental efficiency and working memory were not specifically explored in this study. Occupational status, however, is an ecological measure that might be sensitive to cognitive deficits such as fatigue and reduced mental speed and efficiency, maybe even more so than the neuropsychological tests administered [31, 32]. The importance of occupation probably reflects the fact that work has positive effects on quality of life and protects people against being stigmatized. King [7] found that not having a job was a major source of dissatisfaction for a subsample in her study and suggested that "counselling on finding purpose in other roles may be beneficial for those who cannot return to work."
Age over 65 years was associated with wellbeing. This is in accordance with some other studies that controlled for somatic health $[7,16]$. One explanation for this may be that even if disease and disability are not welcome, they may be more or less expected as a part of life at an older age.

As expected, the tendency to perceive proxies as being supportive predicted wellbeing in the patients. Surprisingly, living alone did not predict reduced wellbeing, and being married or cohabiting did not predict fewer symptoms of emotional distress in this study group. On the contrary, a nonsignificant tendency was found in the opposite direction. Post hoc, closer inspection of the responses (data not shown) showed a significant difference in the two GHQ-30 items related to feeling useful and enjoying ones' daily activities. This may indicate that people living alone experience the feeling of having become a burden to their loved ones to a lesser degree, and they are less inclined towards passivity in their everyday living. The Norwegian welfare system, which makes the citizens less dependent on marriage for their economic welfare or practical help in everyday living, may also contribute to this finding.

Lastly and hardly surprisingly, we found that emotional distress at followup clearly explains wellbeing at followup and vice versa $[11,33]$. While earlier studies primarily focused on depression as a predictor of wellbeing and quality of life $[11,33]$, this study found that the direction of the association between wellbeing at followup and emotional distress at followup goes both ways.

\section{Strengths and Limitations of the Study}

The study group consisted of 68 participants, which is comparable to the few other studies that were undertaken on emotional outcomes in stroke survivors several years after discharge from hospital. A new study on a larger number of participants would provide a stronger power to the statistical 
analyses and is recommended. Prospective longitudinal studies, where subacute emotional symptoms are also systematically assessed, would be welcome.

The strength of this study was that the functional level of the study group was relatively poor compared to the stroke survivors in other studies, where severely injured patients were commonly excluded [34, 35]. The stroke population in the present study was also quite young (mean age of 58 years), which is representative of the population that is commonly seen in rehabilitation medicine hospitals, but not of the general stroke population usually investigated. As with most studies on stroke survivors, a limitation was that patients with the lowest verbal functioning had to be excluded, since the ability to at least be able to reply "yes" or "no" to a simple question was necessary for inclusion in the study. The relatively high proportion of participants with aphasia in this study, with nearly $30 \%$ being dependent in communication, was higher than typically found in studies of stroke populations [36]. This strength of the study might reflect the fact that proxies were allowed to assist in answering the questionnaires.

Information regarding the influence of medical characteristics on the outcome was restricted to the information contained in the medical charts at Sunnaas Hospital. We had no information about the use of medication at followup, which could have potentially influenced the situation regarding symptoms.

\section{Conclusions and Clinical Implications}

The primary finding in this study was that disability and dependency in the activities of daily living are serious threats to long-term mental health. It is important to identify those at risk of developing chronic emotional problems at an early stage of recovery. Interventions can then be correctly focused and concentrated on those most at risk, preferably prophylactic or psychological interventions and medical treatment. Training focused on increasing toilet independence, and mobility should likewise receive high priority in the rehabilitation process. It is important to facilitate vocational activities or meaningful activities outside the home after severe stroke. Proxies who are perceived as being supportive have a positive influence on the wellbeing of patients. More emphasis should also be given on the support that carers of stroke survivors provide.

\section{Conflict of Interests}

The authors declared that they have no conflict of interests.

\section{Funding}

Financial support was partly provided by the Sunnaas Rehabilitation Hospital.

\section{Acknowledgments}

The authors would like to acknowledge the moral support, and encouragement was given by the staff.

\section{References}

[1] V. L. Feigin, C. M. Lawes, D. A. Bennett, S. L. Barker-Collo, and V. Parag, "Worldwide stroke incidence and early case fatality reported in 56 population-based studies: a systematic review," The Lancet Neurology, vol. 8, no. 4, pp. 355-369, 2009.

[2] T. B. Wyller, E. Bautz-Holter, and J. Holmen, "Prevalence of stroke and stroke-related disability in North Trøndelag County, Norway," Cerebrovascular Disease, vol. 4, pp. 421-427, 1994.

[3] C. S. Castillo, S. K. Schultz, and R. G. Robinson, "Clinical correlates of early-onset and late-onset poststroke generalized anxiety," American Journal of Psychiatry, vol. 152, no. 8, pp. 11741179, 1995.

[4] M. L. Hackett, C. Yapa, V. Parag, and C. S. Anderson, "Frequency of depression after stroke: a systematic review of observational studies," Stroke, vol. 36, no. 6, pp. 1330-1340, 2005.

[5] J. W. Sturm, G. A. Donnan, H. M. Dewey et al., "Quality of life after stroke: the North East Melbourne Stroke Incidence Study (NEMESIS)," Stroke, vol. 35, no. 10, pp. 2340-2345, 2004.

[6] F. J. Carod-Artal, L. F. Coral, D. S. Trizotto, and C. M. Moreira, "Poststroke depression: prevalence and determinants in Brazilian stroke patients," Cerebrovascular Diseases, vol. 28, no. 2, pp. 157-165, 2009.

[7] R. B. King, "Quality of life after stroke," Stroke, vol. 27, no. 9, pp. 1467-1472, 1996.

[8] M. Astrom, "Generalized anxiety disorder in stroke patients: a 3-year longitudinal study," Stroke, vol. 27, no. 2, pp. 270-275, 1996.

[9] A. F. G. Leentjens, I. Aben, J. Lodder, and F. R. J. Verhey, "General and disease-specific risk factors for depression after ischemic stroke: a two-step Cox regression analysis," International Psychogeriatrics, vol. 18, no. 4, pp. 739-748, 2006.

[10] E. Stordal, I. Bjelland, A. A. Dahl, and A. Mykletun, "Anxiety and depression in individuals with somatic health problems. The Nord-Trøndelag Health Study (HUNT)," Scandinavian Journal of Primary Health Care, vol. 21, no. 3, pp. 136-141, 2003.

[11] C. Haacke, A. Althaus, A. Spottke, U. Siebert, T. Back, and R. Dodel, "Long-term outcome after stroke: evaluating healthrelated quality of life using utility measurements," Stroke, vol. 37, no. 1, pp. 193-198, 2006.

[12] B. Löfgren, L. Nyberg, M. Mattsson, and Y. Gustafson, “Three years after in-patient stroke rehabilitation: a follow-up study," Cerebrovascular Diseases, vol. 9, no. 3, pp. 163-170, 1999.

[13] M. Astrom, R. Adolfsson, and K. Asplund, "Major depression in stroke patients: a 3-year longitudinal study," Stroke, vol. 24, no. 7, pp. 976-982, 1993.

[14] A. J. Carson, S. MacHale, K. Allen et al., "Depression after stroke and lesion location: a systematic review," Lancet, vol. 356, no. 9224, pp. 122-126, 2000.

[15] M. L. Hackett, J. R. Duncan, C. S. Anderson, J. B. Broad, and R. Bonita, "Health-related quality of life among long-term survivors of stroke: results from the Auckland stroke study, 19911992," Stroke, vol. 31, no. 2, pp. 440-447, 2000.

[16] M. D. Patel, C. McKevitt, E. Lawrence, A. G. Rudd, and C. D. A. Wolfe, "Clinical determinants of long-term quality of life after stroke," Age and Ageing, vol. 36, no. 3, pp. 316-322, 2007.

[17] H. Bergersen, K. F. Frøslie, K. Stibrant Sunnerhagen, and A. K. Schanke, "Anxiety, depression, and psychological well-being 2 to 5 years poststroke," Journal of Stroke and Cerebrovascular Diseases, vol. 19, no. 5, pp. 364-369, 2010. 
[18] A. S. Zigmond and R. P. Snaith, "The hospital anxiety and depression scale," Acta Psychiatrica Scandinavica, vol. 67, no. 6, pp. 361-370, 1983.

[19] D. Goldberg, K. Bridges, P. Duncan-Jones, and D. Grayson, "Detecting anxiety and depression in general medical settings," British Medical Journal, vol. 297, no. 6653, pp. 897-899, 1988.

[20] I. Bjelland, A. A. Dahl, T. T. Haug, and D. Neckelmann, "The validity of the hospital anxiety and depression scale: an updated literature review," Journal of Psychosomatic Research, vol. 52, no. 2, pp. 69-77, 2002.

[21] I. Aben, J. Denollet, R. Lousberg, F. Verhey, F. Wojciechowski, and A. Honig, "Personality and vulnerability to depression in stroke patients: a 1-year prospective follow-up study," Stroke, vol. 33, no. 10, pp. 2391-2395, 2002.

[22] G. Johnson, P. W. Burvill, C. S. Anderson, K. Jamrozik, E. G. Stewart-Wynne, and T. M. H. Chakera, "Screening instruments for depression and anxiety following stroke: experience in the Perth community stroke study," Acta Psychiatrica Scandinavica, vol. 91, no. 4, pp. 252-257, 1995.

[23] A. B. Smith, E. P. Wright, R. Rush, D. P. Stark, G. Velikova, and P. J. Selby, "Rasch analysis of the dimensional structure of the hospital anxiety and depression scale," Psycho-Oncology, vol. 15, no. 9, pp. 817-827, 2006.

[24] J. P. S. Burn and C. D. A. Wolfe, "Reliability of the modified Rankin Scale," Stroke, vol. 23, no. 3, p. 438, 1992.

[25] K. Vardeberg, M. Kolsrud, and T. Laber, "The Sunnaas index of ADL," World Federation of Occupational Therapy Bulletin, pp. 30-35, 1991.

[26] R. A. Keith, C. V. Granger, B. B. Hamilton, and F. S. Sherwin, "The functional independencr measure: a new tool for rehabilitation," in Advances in Clinical Rehabilitation, M. Eisenberg and R. C. Grzeiakre, Eds., vol. 1, pp. 6-18, Springer, New York, NY, USA, 1987.

[27] M. L. Hackett and C. S. Anderson, "Predictors of depression after stroke: a systematic review of observational studies," Stroke, vol. 36, no. 10, pp. 2296-2301, 2005.

[28] F. J. Carod-Artal, D. S. Trizotto, L. F. Coral, and C. M. Moreira, "Determinants of quality of life in Brazilian stroke survivors," Journal of the Neurological Sciences, vol. 284, no. 1-2, pp. 63-68, 2009.

[29] J. H. White, M. K. Alston, J. L. Marquez et al., "Communitydwelling stroke survivors: function is not the whole story with quality of life," Archives of Physical Medicine and Rehabilitation, vol. 88, no. 9, pp. 1140-1146, 2007.

[30] M. Laaksonen, K. Talala, T. Martelin et al., "Health behaviours as explanations for educational level differences in cardiovascular and all-cause mortality: a follow-up of 60,000 men and women over 23 years," European Journal of Public Health, vol. 18, no. 1, pp. 38-43, 2008.

[31] M. Hommel, S. T. Miguel, B. Naegele, N. Gonnet, and A. Jaillard, "Cognitive determinants of social functioning after a first ever mild to moderate stroke at vocational age," Journal of Neurology, Neurosurgery and Psychiatry, vol. 80, no. 8, pp. 876-880, 2009.

[32] A. Jaillard, B. Naegele, S. Trabucco-Miguel, J. F. LeBas, and M. Hommel, "Hidden dysfunctioning in subacute stroke," Stroke, vol. 40, no. 7, pp. 2473-2479, 2009.

[33] A. C. Jönsson, I. Lindgren, B. Hallström, B. Norrving, and A. Lindgren, "Determinants of quality of life in stroke survivors and their informal caregivers," Stroke, vol. 36, no. 4, pp. 803808, 2005.
[34] H. Fjæartoft, B. Indredavik, R. Johnsen, and S. Lydersen, "Acute stroke unit care combined with early supported discharge. Long-term effects on quality of life. A randomized controlled trial," Clinical Rehabilitation, vol. 18, no. 5, pp. 580-586, 2004.

[35] G. Silvestrelli, L. Parnetti, N. Tambasco et al., "Characteristics of delayed admission to stroke unit," Clinical and Experimental Hypertension, vol. 28, no. 3-4, pp. 405-411, 2006.

[36] P. M. Pedersen, H. S. Jørgensen, H. Nakayama, H. O. Raaschou, and T. S. Olsen, "Aphasia in acute stroke: incidence, determinants, and recovery," Annals of Neurology, vol. 38, no. 4, pp. 659666, 1995. 


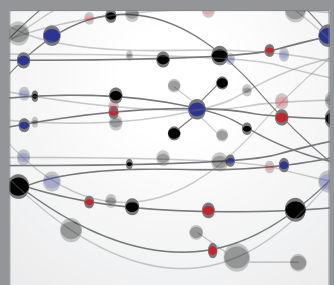

The Scientific World Journal
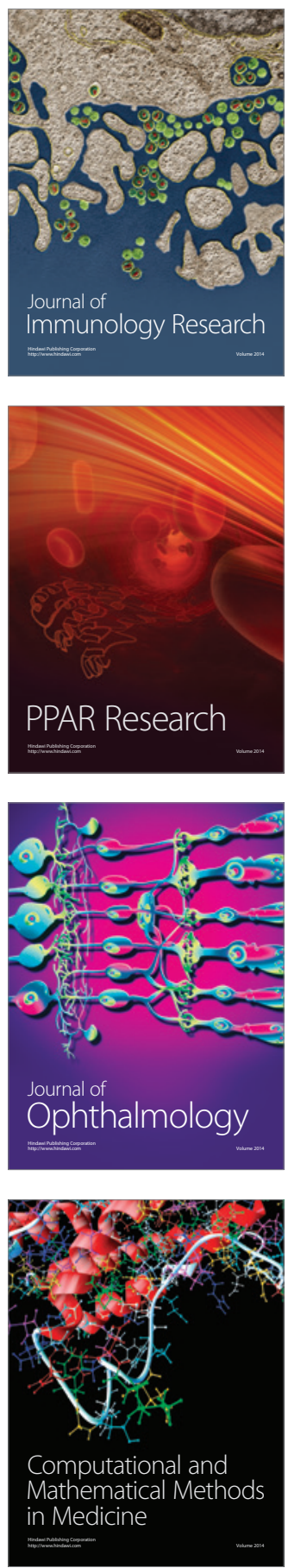

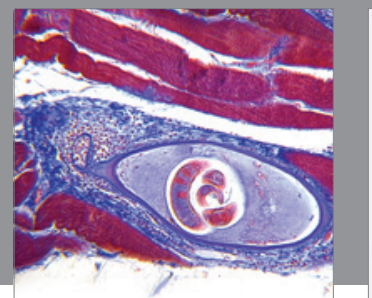

Gastroenterology

Research and Practice
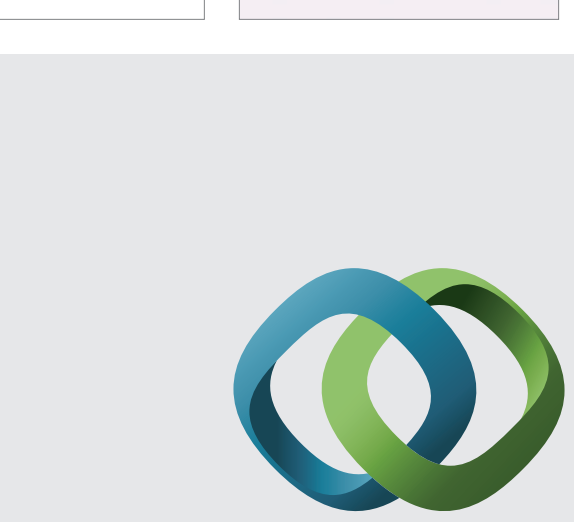

\section{Hindawi}

Submit your manuscripts at

http://www.hindawi.com
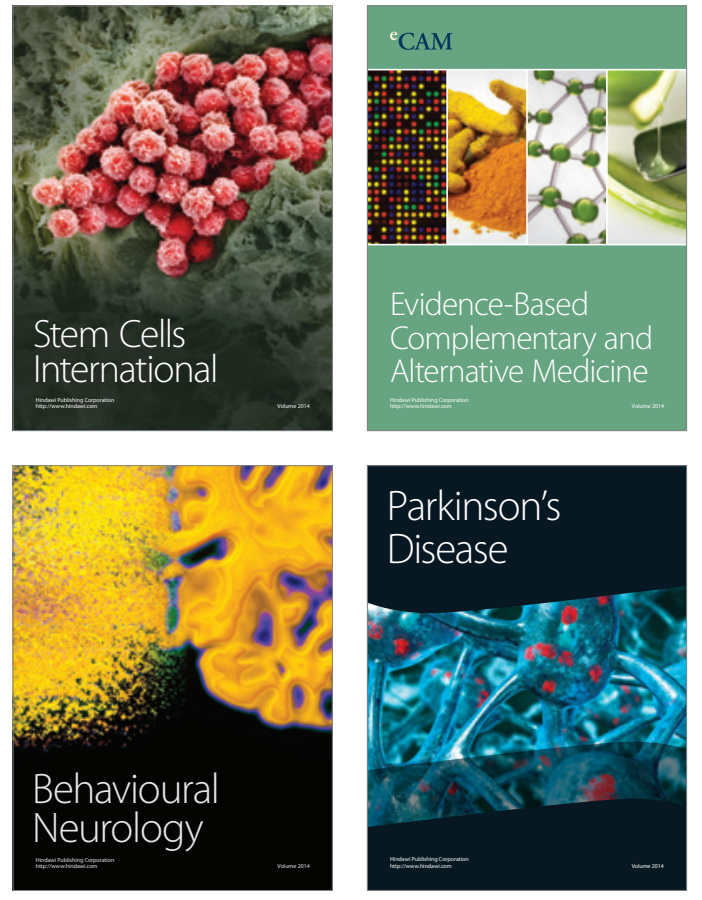
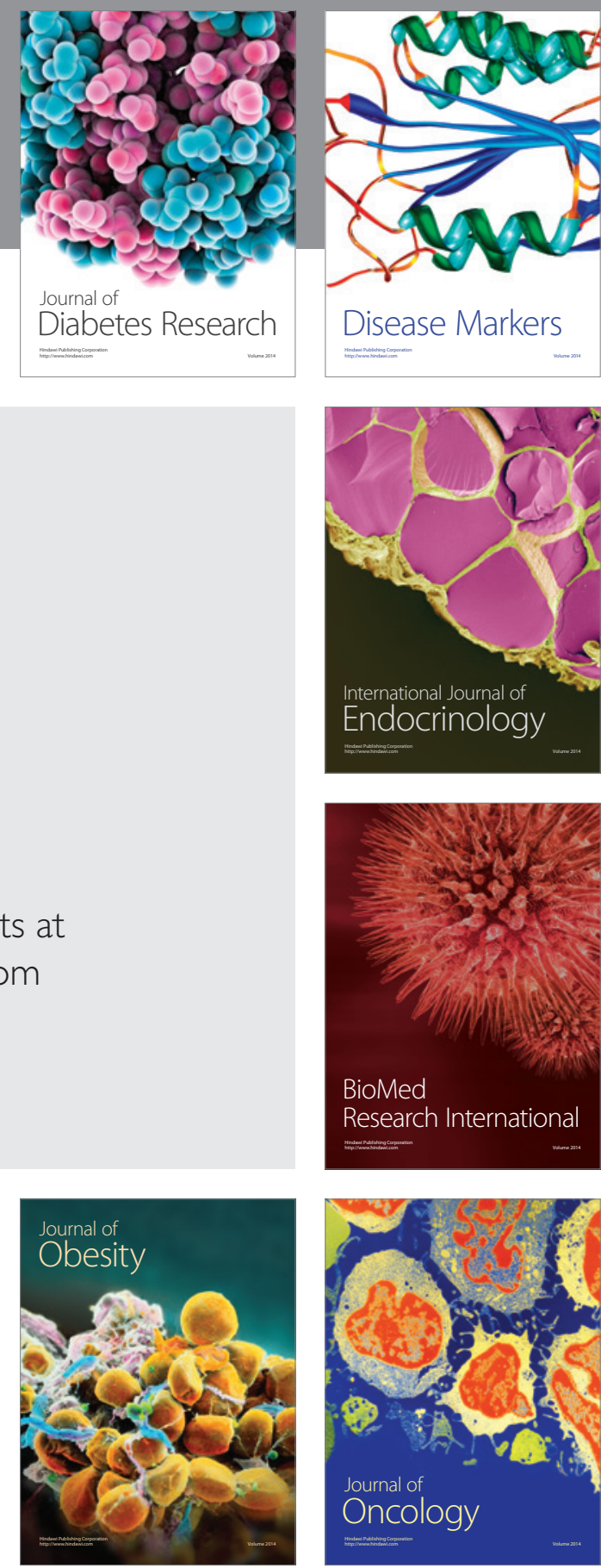

Disease Markers
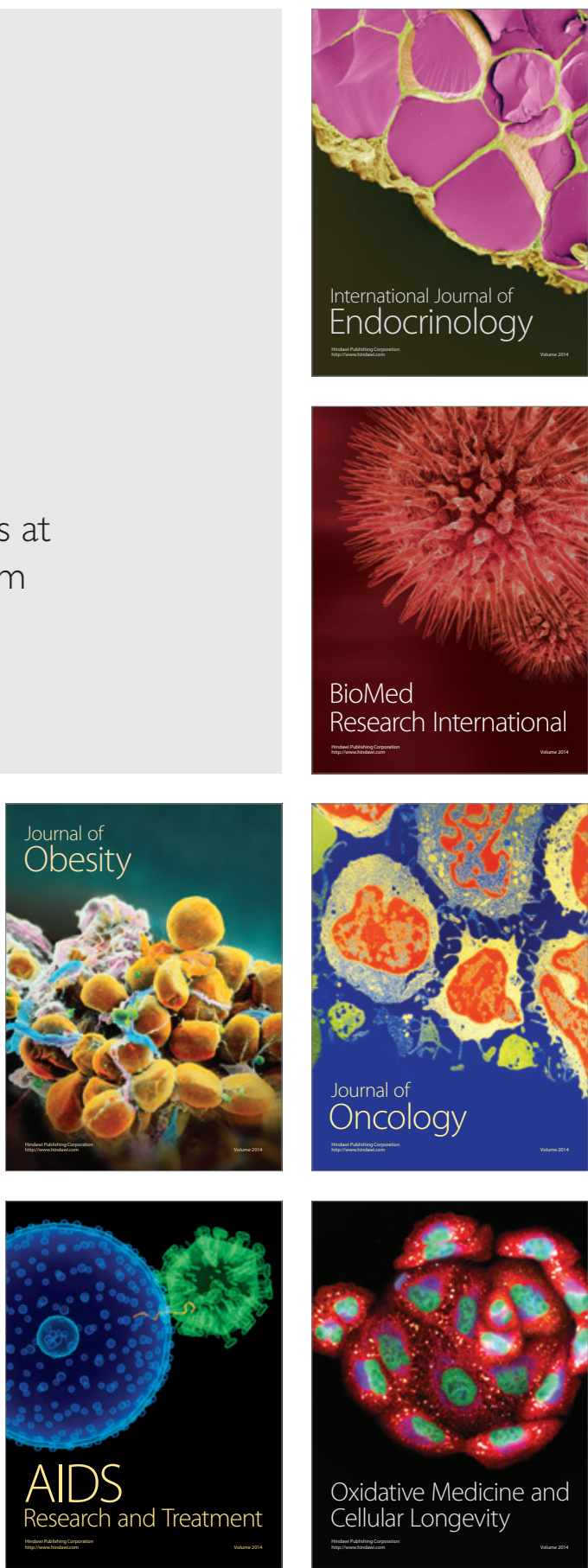